\title{
PERENCANAAN AGREGAT UNTUK MEMENUHI PERMINTAAN IKAN BANDENG TANPA DURI PADA IKM 88 MARIJO DI KABUPATEN PINRANG
}

\author{
${ }^{1)}$ A. Haslindah, ${ }^{2)}$ Suradi, ${ }^{3)}$ Suab Sahi, ${ }^{4)}$ Sartika \\ ${ }^{1,2)}$ Dosen Program Studi Teknik Industri Fakultas Teknik Universitas Islam Makassar \\ ${ }^{3,4)}$ Mahasiswa Program Studi Teknik Industri Fakultas Teknik Universitas Islam Makassar \\ Jl.Perintis Kemerdekaan KM 9 NO 29 Kampus UIM, Tlpn 0411-588-167 \\ Email : andihaslindah.dty@uim-makassar.ac.id
}

\begin{abstract}
ABSTRAK
Perencanaan agregat (agregat planning) adalah suatu pendekatan yang biasanya dilakukan oleh perusahaan untuk menentukan kuantitas dan waktu produksi pada jangka menengah ( biasanya antara 3 hingga 12 bulan ke depan). Perencanaan agregat dapat digunakan dalam menentukan jalan terbaik untuk memenuhi permintaan yang diprediksi dengan menyesuaikan nilai produksi, tenaga kerja, tingkat persediaan, pekerja lembur, subkontrak dan variable lain yang dapat dikendalikan. Untuk metode strategi murni perencanaan agregat didapatkan hasil biaya produksi yang beragam dimana Plan pertama adalah Rp 334.017.500, Plan kedua adalah Rp 338.021.050, Plan ketiga adalah Rp 300.803.500, dan Plan keempat adalah Rp 339.421.750. Sedangkan untuk metode Transportasi adalah Rp 211.851.636, Sehingga dapat dikatakan alternatif dengan biaya minimum adalah metode Transportasi. sehingga metode inilah yang akan digunakan sebagai rujukan dalam perencanaan produksi ikan bandeng tanpa duri pada IKM 88 Marijo
\end{abstract}

Kata Kunci: Perencanaan Agregat, IKM

\section{PENDAHULUAN}

\subsection{Latar Belakang}

Di dalam merencanakan suatu proses produksi, dikenal beberapa metode perencanaan, seperti metode EOQ (Economic Order Quantity), metode perencanaan agregat (agregat planning), metode MRP (Material Requirement Planning) dan masih banyak metode-metode lainnya. Namun di dalam penelitian ini, peneliti hanya akan membahas mengenai perencanaan agregat, dimana Perencanaan agregat (agregat planning) adalah suatu pendekatan yang biasanya dilakukan oleh perusahaan untuk menentukan kuantitas dan waktu produksi pada jangka menengah ( biasanya antara 3 hingga 12 bulan ke depan). Perencanaan agregat dapat digunakan dalam menentukan jalan terbaik untuk memenuhi permintaan yang diprediksi dengan menyesuaikan nilai produksi, tenaga kerja, tingkat persediaan, pekerja lembur, subkontrak dan variable lain yang dapat dikendalikan.

Didalam penerapannya, tidak semua perusahaan melakukan suatu proses perencanaan produksi seperti perencanaan agregat. Seperti yang terjadi pada IKM 88 Marijo yang memproduksi Ikan Bandeng tanpa duri. Jumlah permintaan Ikan Bandeng tanpa duri dari bulan Januari sampai Desember 2013 mencapai 86.936 bungkus sedangkan jumlah produksi rata-rata perbulan sekitar 5.010 bungkus Sehingga IKM 88 Marijo kewalahan dalam memenuhi permintaan pelanggan karena jumlah permintaan sulit diprediksi. Jika hal tersebut terjadi maka pelanggan akan merasa kecewa dan pindah ke tempat lain untuk membeli produk yang sama. Oleh karena itu, dibutuhkan suatu perencanaan produksi agar jumlah permintaan bisa terpenuhi. 


\subsection{Rumusan Masalah}

Dari latar belakang diatas, maka dapat ditarik rumusan masalah yaitu:

a. Bagaimana memenuhi permintaan Ikan Bandeng tanpa duri menggunakan Perencanaan Agregat?

b. Bagaimana menghitung Perbandingan antara Metode Strategi Murni dan Metode Transportasi dalam Perencanaan Agregat?

\subsection{Tujuan Penelitian}

Penelitian ini bertujuan :

a. Memenuhi Permintaan Ikan Bandeng tanpa duri menggunakan Perencanaan Agregat

b. Menghitung Perbandingan antara metode Strategi Murni dan Metode Transportasi dalam Perencanaan Agregat.

\section{METODOLOGI PENELITIAN}

\subsection{Waktu dan Tempat}

Penelitian ini dilaksanakan pada industri pengolahan Ikan Bandeng menjadi Ikan Bandeng tanpa duri pada IKM 88 Marijo di Jalan Poros Pare - Pinrang Kelurahan Manarang Kecamatan Mattiro Bulu Kabupaten Pinrang.

\subsection{Jenis Penelitian}

Jenis penelitian yang digunakan adalah penelitian deskriptif yaitu penelitian yang memberikan gambaran atau uraian tanpa ada perlakuan terhadap obyek yang diteliti.

\subsection{Metode Pengumpulan Data}

Metode pengumpulan dilakukan dengan beberapa cara yaitu :

a. Observasi lapangan yaitu pengumpulan data dengan mengadakan pengamatan langsung di lokasi penelitian.

b. Wawancara yaitu pengumpulan data dengan mengadakan tanya jawab secara langsung dengan Pimpinan IKM 88 Marijo serta karyawannya.

c. Studi Pustaka yaitu dengan melakukan perbandingan serta mengambil landasan teori tertentu yang berhubungan dengan pembahasan yang penulis sajikan.

\section{ANALISA DAN PEMBAHASAN}

Berdasarkan uraian di atas maka metode peramalan yang terpilih adalah metode yang memiliki Standar Error (SE) yang terkecil yaitu : 773,09 (Seasonal additive) Seperti yang terlihat pada Tabel 4.17 berikut ini.

Tabel 3. Hasil Standart Eror terkecil Metode Peramalan

\begin{tabular}{lccc}
\hline Metode Peramalan & SE & MSE & MAD \\
\hline Moving Average & 1468 & 1763208 & 889.64 \\
Exponential & 1106.98 & 1002607 & 709.34 \\
Smoothing & 838.52 & 585923.5 & 615.7 \\
Linier Regresi & $\mathbf{7 7 3 . 0 9}$ & $\mathbf{3 9 8 4 5 0 . 1}$ & $\mathbf{5 2 2 . 5 4}$ \\
\hline Seasonal Additive & & & \\
\hline
\end{tabular}

a. Rata-rata Deviasi Mutlak(Mean Absolute Deviation $=\mathrm{MAD}$ )

$$
\begin{aligned}
\operatorname{MAD} & =\frac{\sum_{\mathrm{t}=1}^{\mathrm{N}}\left|\mathrm{d}_{\mathrm{t}-} \mathrm{d}_{\mathrm{t}}{ }_{\mathrm{t}}\right|}{\mathrm{N}} \\
& =\frac{6230,97}{12} \\
& =522.54
\end{aligned}
$$

b. Rata-rata Kuadrat Kesalahan (Mean square Error $=$ MSE)

$$
\begin{aligned}
\text { MSE } & =\frac{\sum_{\mathrm{t}=1}^{\mathrm{N}}\left(\mathrm{d}_{\mathrm{t}}-\mathrm{d}_{\mathrm{t}}^{\prime}\right)^{2}}{\mathrm{~N}} \\
& =\frac{6011607}{12} \\
& =398450,1
\end{aligned}
$$

c. Standar Error Estimate (SEE)

$$
\begin{aligned}
\mathrm{SEE}= & \sqrt{\sum_{\mathrm{t}=1}^{\mathrm{n}} \frac{\left(\mathrm{d}_{\mathrm{t}}-\mathrm{d}_{\mathrm{t}}^{\prime}\right)^{2}}{(\mathrm{~N}-2}} \\
& =\frac{\sqrt{6011607}}{10} \\
& =773,09
\end{aligned}
$$

Untuk menentukan metode agregat yang tepat untuk digunakan pada IKM 88 Marijo Berikut ini data peramalan 1 tahun ke depan dengan menggunakan metode seasonal additive. Data hasil peramalan ini akan dijadikan landasan untuk pengolahan perencanaan agregat. 
Tabel 4.18 : Data Permintaan dimasa mendatang

\begin{tabular}{ccc}
\hline Tahun & Bulan & Jumlah permintaan \\
\hline 2014 & Januari & 8349 \\
\cline { 2 - 3 } & Februari & 7691 \\
\cline { 2 - 3 } & Maret & 8571 \\
\cline { 2 - 3 } & April & 7912 \\
\cline { 2 - 3 } Mei & 8792 \\
\hline Juni & 8134 \\
\hline Juli & 9014 \\
\hline Agustus & 8355 \\
\hline September & 9235 \\
\cline { 2 - 2 } & Oktober & 8577 \\
\cline { 2 - 2 } & November & 9457 \\
\cline { 2 - 2 } & Desember & 8798 \\
\cline { 2 - 2 } & $\begin{array}{c}\text { Total } \\
\text { permintaan }\end{array}$ & $\mathbf{1 0 2 8 8 5}$ \\
\hline
\end{tabular}

Setelah diperoleh Permintaan dimasa mendatang, maka dilakukan Perencanaan Agregat dengan melakukan Perbandingan antara metode strategi murni dan metode transportasi.

Untuk metode strategi murni perencanaan agregat didapatkan hasil biaya produksi yang beragam dimana Plan pertama adalah Rp 334.017.500, Plan kedua adalah Rp 338.021.050, Plan ketiga adalah Rp 300.803.500, dan Plan keempat adalah $\mathrm{Rp}$ 339.421.750. Sedangkan untuk metode Transportasi adalah Rp 211.851.636, Sehingga dapat dikatakan alternatif dengan biaya minimum adalah metode Transportasi. sehingga metode inilah yang akan digunakan sebagai rujukan dalam perencanaan produksi ikan bandeng tanpa duri pada IKM 88 Marijo.
Tabel 4.19 Perbandingan Metode

\begin{tabular}{|c|c|c|c|c|c|}
\hline \multirow{2}{*}{ Biaya } & \multicolumn{4}{|c|}{ Metode Strategi Murni } & \multirow{2}{*}{$\begin{array}{c}\text { Metode } \\
\text { Transp } \\
\text { ortasi } \\
\end{array}$} \\
\hline & Plan 1 & Plan 2 & Plan 3 & Plan 4 & \\
\hline $\begin{array}{c}\text { Rekrut } \\
\text { TK }\end{array}$ & 175.000 & & & & \\
\hline PHK & 907.500 & & & & \\
\hline $\begin{array}{c}\text { Kelebiha } \\
\mathrm{n} \\
\text { persediaa } \\
\mathrm{n}\end{array}$ & & & & 3.501 .750 & \\
\hline $\begin{array}{l}\text { Kekuran } \\
\text { gan }\end{array}$ & & $\begin{array}{c}2.101 .05 \\
0\end{array}$ & & & \\
\hline $\begin{array}{c}\text { Subkontr } \\
\text { ak }\end{array}$ & & & $\begin{array}{c}9.643 .50 \\
0\end{array}$ & & \\
\hline \multicolumn{6}{|l|}{ Overtime } \\
\hline $\begin{array}{c}\text { Jam } \\
\text { regular }\end{array}$ & $\begin{array}{c}332.935 . \\
000\end{array}$ & $\begin{array}{c}335.920 \\
000\end{array}$ & $\begin{array}{c}291.160 . \\
000\end{array}$ & $\begin{array}{c}335.920 .0 \\
00\end{array}$ & \\
\hline $\begin{array}{c}\text { Biaya } \\
\text { Produksi }\end{array}$ & & & & & $\begin{array}{c}61.851 . \\
636\end{array}$ \\
\hline $\begin{array}{c}\text { Biaya } \\
\text { Persedia } \\
\text { an awal }\end{array}$ & & & & & $\begin{array}{c}150.00 \\
0.000\end{array}$ \\
\hline TOTAL & $\begin{array}{c}334.017 \\
500\end{array}$ & $\begin{array}{c}338.021 \\
050\end{array}$ & $\begin{array}{c}300.803 \\
500\end{array}$ & $\begin{array}{c}339.421 .7 \\
50\end{array}$ & $\begin{array}{c}211.85 \\
1.636\end{array}$ \\
\hline
\end{tabular}

\section{PENUTUP}

\subsection{Kesimpulan}

Dari hasil pembahasan diatas, maka dapat ditarik kesimpulan yaitu:

1. Perencanaan agregat dapat digunakan dalam memenuhi permintaan ikan bandeng tanpa duri.

2. Setelah dilakukan perbandingan antara metode strategi murni dan metode transportasi. Diperoleh metode strategi murni perencanaan agregat dengan hasil biaya produksi yang beragam dimana Plan I adalah Rp 334.017.500, Plan II adalah Rp 338.021.050, Plan III adalah Rp 300.803.500, dan Plan IV adalah Rp 339.421.750. Sedangkan untuk metode Transportasi adalah Rp 211.851.636. Sehingga Perencanaan agregat yang paling optimal untuk diaplikasikan pada IKM 88 Marijo yaitu Metode Transportasi dengan biaya produksi sebesar Rp. 211.851.636 


\subsection{Saran}

Untuk mengoptimalkan hasil penelitian ini, maka peneliti menyarankan kepada IKM 88 Marijo sebagai berikut :

1. Sebaiknya dalam menjalankan usahanya pemilik IKM 88 Marijo menggunakan perencanaan produksi agar permintaan konsumen akan produk ikan bandeng tanpa duri dapat terpenuhi.

2. Sebaiknya IKM 88 Marijo menerapkan perencanaan produksi agregat dengan metode transportasi guna memenuhi permintaan ikan bandeng tanpa duri yang semakin meningkat pada setiap bulannya.

\section{DAFTAR PUSTAKA}

Ahmad, L. 2011. Sistem Produksi. Cahaya Baliputra : Makassar.

Assauri, S. 2009. Manajemen produksi dan operasi. Lembaga penerbit FE UI ; Jakarta

Cahyono. B, Ir. 2011. Budidaya Ikan Bandeng Tambak Payau dan Tambak Sawah. Pustaka Mina, Jakarta

Edy Herjanto, 2007. Manajemen Operasi edisi ketiga. Jakarta: PT Grasindo

Galaxy Ilmu, 2009. (Perencanaan Agregat) http://galaxyilmu.blogspot.com/2009/peren canaan-agregat\%20br.html (download 2 januari 2014);

Hakim, Arman DKK. 2008. Perencanaan dan Pengendalian Produksi. Graha Ilmu ; Yogyakarta

Mariana Lily. 2012 Artikel ikan Bandeng Tanpa Duri (Widyaiswara PPPPTK Pertanian)

Menara ilmu. 2012 (Peramalan dan Perencanaan Agregat Bag. 2) http://menarailmu.blogspot.com/2012/pera malan-dan-perencanaan-agregat-bag2.html (download 15 Desember 2013);

Wikipedia.2013. http://id.wikipedia.org/wiki/Bandeng [Download 28-12-2013]

Lebih Ergonomis pada Stasiun Kerja Perakitan dan Pemolesan di PT. YPTI, Jun 15 th, 2007 by admin.

\section{Ergonomi}

Industri,

http://adibuana.com/web. Universitas PGRI Adibuana Surabaya (2008). 